(2) Open Access Full Text Article

\title{
Perspectives and experiences of Thai adults using wheelchairs regarding barriers of access to dental services: a mixed methods study
}

This article was published in the following Dove Press journal:

Patient Preference and Adherence

\section{Nithimar Sermsuti-anuwat Sathirakorn Pongpanich \\ College of Public Health Sciences, Chulalongkorn University, Bangkok, Thailand}

Purpose: To explore the perspectives and experiences of Thai wheelchair users regarding barriers of access to dental services and report potential solutions in terms of customer satisfaction.

Participants and methods: We conducted a 2-phase cross-sectional study with quantitative and qualitative components at a community club for individuals with disabilities in Pathum Thani province, Thailand, in February 2018. In quantitative phase, participants were interviewed using a structured questionnaire that consisted of 1) questions on demographic characteristics and 2) adapted questions that were based on the modified Penchansky and Thomas dimensions of access. Enter method of binary logistic regression analysis was used. Regarding qualitative phase, focus group discussions were conducted using the themes of a semi-structured discussion guide. Thematic analysis was used.

Results: A total of 156 wheelchair users participated in the quantitative phase. Most study participants had not attended dental care services in the previous year (78.2\%). Multivariate analysis found a statistically significant association that indicated that participants who had education level $\leq$ primary education were 3.5 times more likely to had not attended a dental appointment in the previous year $(P=0.003)$. In the qualitative phase, 33 participants were included in 3 focus groups (each comprising 11 participants), they were wheelchair users with education $>$ primary, who did not go to see a dentist in the previous 12 months. Findings of the 3 focus groups suggest generally negative views about Thai dental services for all dimensions of access.

Conclusion: This study reflects the unheard voices of wheelchair users and provides rigorous evidence in Thai context that difficulties of access to dental services persist. Policy makers and oral health professionals in oral health system should be alerted to the explicit barriers reported, such that equitable and equal dental services for disabled individuals can be developed.

Keywords: barriers to care, dental service, wheelchair user, physical disabilities, focus group, Thailand

\section{Introduction}

In 2015 , the $\mathrm{WHO}^{1}$ reported that there are $\sim 1$ billion individuals living with disabilities globally, estimated at $15 \%$ of the world population. Indeed, previous studies ${ }^{2-6}$ have reported that individuals with disabilities experience poorer oral health than individuals without disabilities, presenting with a greater number of dental cavities and increased risk of periodontal diseases. Due to the daily lives of individuals with disabilities are limited, such limitations can include difficulty functioning, the presence of comorbidities, and a lack of well-organized dental care services for individuals with special needs. ${ }^{2,3,7,8}$ 
Good oral health is a basic human right, and disabled individuals are equally inclined to preserve their natural teeth for the same reasons as individuals without disabilities, including enjoyable eating, improved physical appearance, enhanced self-confidence, increased social acceptance, general well-being, and good quality of life. ${ }^{69}$ Moreover, all individuals should have access to health care systems and oral health care services of an equal quality to achieve equitable outcomes. ${ }^{4,9}$

A 2012 national survey of disability from the National Statistical Office of Thailand, ${ }^{10}$ indicated that there are 1.5 million Thai individuals with disabilities, comprising an estimated $2.2 \%$ of the total Thai population. Furthermore, the number increases among older Thai nationals. ${ }^{11}$ The main type of disability (nearly 50\%) is physical disabilities. Although $92.1 \%$ of disabled Thai citizens have health care benefits under the government universal health coverage (UHC), 98.7\% have current health problems. ${ }^{10}$ Moreover, Thai individuals with disabilities may experience poor oral health but there has not yet been a national oral health survey of the disabled population of Thailand. As such, the difficulties to accessing dental services among Thai adults with physical disabilities who are wheelchair users have not previously been identified.

Therefore, the purpose of this study was to explore the perspectives and experiences of Thai adults using wheelchairs regarding barriers of access to dental services, and report potential solutions in terms of customer satisfaction.

\section{Materials and methods}

We conducted a 2-phase cross-sectional study with quantitative and qualitative components at a community club for individuals with disabilities in Pathum Thani province, Thailand, in February 2018. The study protocol was approved by the Research Ethics Review Committee for Research Involving Human Research Participant, Health Sciences Group, Chulalongkorn University, Thailand (No 012/2018), which has approved in accordance with the International Conference on Harmonization - Good Clinical Practice (ICH-GCP). Informed consent was obtained for participation; the information sheets were read by one of the authors, assuring the comprehension of the information statement for all subjects. Participants signed to inform that their responses were anonymous and confidential.

\section{Participants}

\section{Quantitative study}

The sample size was calculated using the formula that was developed by Cochran as mentioned in a prior study, ${ }^{12}$ where the attendance of wheelchair users in dental health services provided in the annual health report (2017) of the Center for Independent Living (a disability community club) was $10 \%$. Considering a drop-out rate of $\sim 10 \%$, a convenient sample of 153 was required.

All members of disability community clubs were invited to participate in this study through an announcement made by the Center of Independent Living, Pathum Thani province, Thailand. Men and women with disabilities were included if they were Thai citizens, aged 18-64 years, permanent wheelchair users, living in residential community households, capable of performing their own daily self-care independently with a score $\geq 12$ on the Thai Modified Barthel Activities of Daily Living (ADL) index. ${ }^{13}$ Exclusion criteria were as follows: Thai people, who were identified on their Thai national identity card as had mental complications, hearing loss, visual impairments, or serious chronic diseases; those who were unable to communicate in Thai language; and those unwilling to be a participant.

\section{Qualitative study}

The sole purpose of quantitative phase was to help identify potential participants for the qualitative study.

We included participants in the qualitative study where there were significant differences in category variables from the quantitative phase between participants who reported they had at least 1 dental visit and those who had not attended a dental care service within the previous year. This allowed us to identify those who appeared to face barriers to dental care to further investigate the perspectives and experiences of these individuals.

\section{Data collection}

\section{Quantitative study}

Individual participants were interviewed by a trained interviewer using a structured questionnaire that consisted of 1) questions on demographic characteristics and 2) adapted questions that were based on the Penchansky and Thomas dimensions of access ${ }^{14}$ and the modified Penchansky and Thomas theory of access. ${ }^{15}$ The latter collected data regarding the following:

- Accessibility: "Is there a convenient dental service for a wheelchair user in terms of time and distance?" (Location)

- Availability: "Are there sufficient dental services and resources to meet the specific needs of wheelchair users and communities?" (Supply and demand)

- Acceptability: "Do wheelchair users find dental service providers acceptable in terms of the characteristics 
of dental services, and social or cultural concerns?" (Consumer's perception)

- Affordability: "Is there an affordable dental service for a wheelchair user?" (Financial and incidental costs)

- Accommodation: "Is there an adequate dental service that well organized for wheelchair users? Consideration of adequacy include hours of dental operation (after-hour dental services), referral or appointment systems, and facility structures (wheelchair access)." (Organization)

- Awareness: "Does dental care maintain awareness through effective communication and information strategies with relevant users (dentists, dental nurses, patients without disabilities, patients with disabilities and community), including consideration of context and oral health literacy?" (oral health information and knowledge)

Three experts in public health validated the contents of the adapted questionnaire through the index of Item-Objective Congruence, $\mathrm{IOC}=0.84$. A pilot test of 30 individuals with physical disabilities from nearby community was conducted to test the internal consistency. The Cronbach's alpha coefficient was 0.89 .

\section{Qualitative study}

Focus group discussions (each focus group contained $\leq 12$ participants) ${ }^{16}$ were conducted by 2 facilitators using the themes of a semi-structured discussion guide that followed the dimensions of access, ${ }^{14,15}$ similar to the structured questionnaire of the quantitative phase. Each focus group was audiotaped and the discussions were completed within 2 hours.

\section{Data analysis Quantitative study}

We compared demographic characteristics and variables for the dimensions of access between participants who had at least 1 dental appointment and those who had not attended dental care in the previous year. We used medians, ranges, and Mann-Whitney $U$ tests for non-normally distributed variables (Barthel ADL scores and age). Fisher's exact tests were calculated for categorical variables, those variables that presented $P<0.25$ were included in logistic regression analyses. Enter method of binary logistic regression analysis was used; initial analyses for identified bivariate comparisons between dental service attendance and demographic characteristics (age, gender, income, and education), including the dimensions of access variables (accessibility, availability, acceptability, affordability, accommodation, and awareness) were performed; the associated independent variables that showed $P$-value $<0.25$ were included in multivariate logistic regression analysis. Quantitative data were analyzed with
SPSS software (version 20; IBM, Chicago, IL, USA). All analyses were 2 -tailed and a $P$-value $<0.05$ was considered statistically significant.

\section{Qualitative study}

Thematic analysis ${ }^{17,18}$ was used to analyze qualitative data according to the following steps: 1) audiotaped recordings were transcribed verbatim, and the authors separately read and re-read the transcriptions, taking note of initial ideas for coding; 2) preliminary coding was conducted by the authors inductively from the summary transcriptions of the focus group discussions (participants' perspectives and experiences); 3 ) preliminary codes were mapped on to related themes and subthemes; 4) preliminary themes and subthemes were reviewed deductively based on the theory of access; ${ }^{14,15}$ and 5) the 2 authors ensured final themes and subthemes had consistently accurate definitions. QSR International's NVivo 11 software was used to facilitate qualitative analysis (Software Version 11; QSR International Pty Ltd., Doncaster, VA, Australia).

\section{Results}

\section{Quantitative study}

Table 1 presents the demographic characteristics of participants included in the quantitative phase. We included 156 wheelchair users who were capable of performing daily self-care, with a median Barthel ADL score of 16 . Patients aged 21-62 years (median: 49 years) completed the structured questionnaires. Most study participants had not attended dental care services in the previous 12 months (78.2\%). For category variables, the major demographic characteristics of the study population aged $\geq 49$ years (63.5\%), male (72.4\%), income $<15,000$ THB ( 475 USD) per month $(78.2 \%), \leq$ primary school $(66.7 \%)$, and gave negative responses for questions regarding the dimensions of access ${ }^{14,15}$ as follows: a total of $78.2 \%$ of the study participants reported "no accessible dental service", $75.6 \%$ reported "no available dental service", $75.6 \%$ reported "no acceptable dental service", $80.1 \%$ reported "no affordable dental service", $80.8 \%$ reported "no accommodating dental service", and $84.6 \%$ reported "no awareness in dental service".

In Table 2, although we did not observe any statistically significant differences in age, gender, income, and the 6 dimensions of access (accessibility, availability, acceptability, affordability, accommodation, and awareness) between those who had attended at least 1 dental appointment in the previous year and those who had not, there was a significant difference in education level between the 2 groups $(P=0.003)$; the independent variables that demonstrated $P<0.25$ in the 
Table I Demographic characteristics participants included in quantitative phase

\begin{tabular}{|c|c|c|}
\hline Variables & $\begin{array}{l}\text { Number or } \\
\text { median (min-max) }\end{array}$ & $\begin{array}{l}\text { Percent or } \\
\text { mean (SD) }\end{array}$ \\
\hline Total ${ }^{a}$ & 156 & 100 \\
\hline Barthel ADL scores & $16(12-19)$ & $15.63(2.06)$ \\
\hline Age (years) & $49(21-62)$ & $48.29(8.70)$ \\
\hline$<49$ years & 57 & 36.5 \\
\hline$\geq 49$ years & 99 & 63.5 \\
\hline \multicolumn{3}{|l|}{ Gender } \\
\hline Female & 43 & 27.6 \\
\hline Male & 113 & 72.4 \\
\hline \multicolumn{3}{|l|}{ Income per month } \\
\hline$\geq 15,000$ THB (475 USD) $)^{b}$ & 34 & 21.8 \\
\hline$<15,000$ THB & 122 & 78.2 \\
\hline \multicolumn{3}{|l|}{ Education } \\
\hline$>$ Primary & 52 & 33.3 \\
\hline$\leq$ Primary & 104 & 66.7 \\
\hline \multicolumn{3}{|l|}{ Attended dental service ${ }^{c}$} \\
\hline Yes & 34 & 21.8 \\
\hline No & 122 & 78.2 \\
\hline \multicolumn{3}{|l|}{ Dimensions of access } \\
\hline \multicolumn{3}{|l|}{ Accessibility } \\
\hline Yes & 34 & 21.8 \\
\hline No & 122 & 78.2 \\
\hline \multicolumn{3}{|l|}{ Availability } \\
\hline Yes & 38 & 24.4 \\
\hline No & 118 & 75.6 \\
\hline \multicolumn{3}{|l|}{ Acceptability } \\
\hline Yes & 38 & 24.4 \\
\hline No & 118 & 75.6 \\
\hline \multicolumn{3}{|l|}{ Affordability } \\
\hline Yes & 31 & 19.9 \\
\hline No & 125 & 80.1 \\
\hline \multicolumn{3}{|l|}{ Accommodation } \\
\hline Yes & 30 & 19.2 \\
\hline No & 126 & 80.8 \\
\hline \multicolumn{3}{|l|}{ Awareness } \\
\hline Yes & 24 & 15.4 \\
\hline No & 132 & 84.6 \\
\hline
\end{tabular}

Notes: ${ }^{a}$ All participants relied on government Universal Health Coverage, including dental benefits. ${ }^{\circ}$ 15,000 Thai Baht (475 US dollars). 'Attended at least I dental care visit in the previous 12 months.

Abbreviations: ADL, activity of daily living; min-max, minimum-maximum.

bivariate analyses were included in binary logistic regression analyses.

Results of simple bivariate and multivariate logistic regression analyses are presented in Table 3 - the simple bivariate analyses showed $P<0.25$ between dental service attendance and age group $(P=0.068)$, education level $(P=0.002)$, including the 3 dimensions of access as follows: accessibility $(P=0.227)$, acceptability $(P=0.097)$, and accommodation $(P=0.093)$, then multivariate logistic regression analysis was performed.

For multivariate analysis, we found a statistically significant association that indicated participants who had education
Table 2 Factors associated with dental services attendance within 12 months of the quantitative phase

\begin{tabular}{|c|c|c|c|}
\hline \multirow[t]{2}{*}{ Variables } & \multicolumn{2}{|c|}{$\begin{array}{l}\text { Attended at least one } \\
\text { dental care service }\end{array}$} & \multirow[t]{2}{*}{$P$-value } \\
\hline & $Y_{e s}^{a}$ & $\mathbf{N o}^{\mathrm{a}}$ & \\
\hline Total & $34(21.8)$ & $122(78.2)$ & \\
\hline \multicolumn{4}{|l|}{ Age (years) } \\
\hline$<49$ years & $17(29.8)$ & $40(70.2)$ & 0.073 \\
\hline$\geq 49$ years & $17(17.2)$ & $82(82.8)$ & \\
\hline \multicolumn{4}{|l|}{ Gender } \\
\hline Female & $12(27.9)$ & $31(72.1)$ & 0.281 \\
\hline Male & $22(19.5)$ & $91(80.5)$ & \\
\hline \multicolumn{4}{|l|}{ Income per month } \\
\hline$\geq 15,000$ THB (475 USD) ${ }^{c}$ & $7(20.6)$ & $27(79.4)$ & 1.000 \\
\hline$<15,000$ THB & $27(22.1)$ & $95(77.9)$ & \\
\hline \multicolumn{4}{|l|}{ Education } \\
\hline$>$ Primary & $19(36.5)$ & $33(63.5)$ & 0.003 \\
\hline$\leq$ Primary & $15(14.4)$ & $89(85.6)$ & \\
\hline \multicolumn{4}{|l|}{ Dimensions of access } \\
\hline \multicolumn{4}{|l|}{ Accessibility } \\
\hline Yes & $10(29.4)$ & $24(70.6)$ & 0.244 \\
\hline No & $24(19.7)$ & $98(80.3)$ & \\
\hline \multicolumn{4}{|l|}{ Availability } \\
\hline Yes & II (28.9) & $27(71.1)$ & 0.259 \\
\hline No & $23(19.5)$ & $95(80.5)$ & \\
\hline \multicolumn{4}{|l|}{ Acceptability } \\
\hline Yes & $12(31.6)$ & $26(68.4)$ & 0.114 \\
\hline No & $22(18.6)$ & $96(81.4)$ & \\
\hline \multicolumn{4}{|l|}{ Affordability } \\
\hline Yes & $9(29.0)$ & $22(7 \mid .0)$ & 0.331 \\
\hline No & $25(20.0)$ & $100(80.0)$ & \\
\hline \multicolumn{4}{|l|}{ Accommodation } \\
\hline Yes & $10(33.3)$ & $20(66.7)$ & 0.137 \\
\hline No & $24(19.0)$ & $102(81.0)$ & \\
\hline \multicolumn{4}{|l|}{ Awareness } \\
\hline Yes & $6(25.0)$ & I $8(75.0)$ & 0.788 \\
\hline No & $28(21.2)$ & $104(78.8)$ & \\
\hline
\end{tabular}

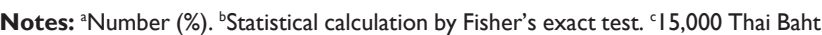
(475 US dollars).

level $\leq$ primary education were nearly 3.5 times more likely to had not attended at least 1 dental appointment in the previous year $(P=0.003)$.

\section{Qualitative study}

Following the quantitative phase, potential participants were subsequently included in the qualitative phase. Participants were chosen based on variables that differed significantly between the 2 study groups (did and did not attend a dental appointment in the previous year). According to the literature, ${ }^{19-21}$ individuals with higher education were likely to have regular dental service attendance. In the quantitative phase, education level was statistically associated with dental service attendance and there were 33 participants that had education level > primary education but did not attend 
Table 3 Simple bivariate and multivariate binary logistic regression analyses of dental services attendance of the quantitative phase

\begin{tabular}{|c|c|c|c|}
\hline Variables & $\begin{array}{l}\text { Crude OR } \\
(95 \% \mathrm{Cl})\end{array}$ & $\begin{array}{l}\text { Adjusted OR } \\
(95 \% \mathrm{Cl})\end{array}$ & $P$-value ${ }^{a}$ \\
\hline Age & & & 0.087 \\
\hline$<49$ years (Ref) & I & 1 & \\
\hline$\geq 49$ years & $2.050(0.948-4.433)$ & $2.045(0.902-4.635)$ & \\
\hline Education & & & 0.003 \\
\hline$>$ Primary (Ref) & 1 & 1 & \\
\hline$\leq$ Primary & 3.416 (I.557-7.497) & 3.488 (1.549-7.854) & \\
\hline \multicolumn{4}{|c|}{ Dimensions of access } \\
\hline Accessibility & & & 0.995 \\
\hline Yes (Ref) & I & I & \\
\hline No & $1.70 \mid(0.7 \mid 8-4.030)$ & $0.996(0.255-3.891)$ & \\
\hline Acceptability & & & 0.587 \\
\hline Yes (Ref) & I & 1 & \\
\hline No & $2.014(0.882-4.601)$ & $1.515(0.338-6.786)$ & \\
\hline Accommodation & & & 0.721 \\
\hline Yes (Ref) & 1 & I & \\
\hline No & $2.125(0.882-5.122)$ & $1.299(0.310-5.435)$ & \\
\hline
\end{tabular}

Notes: The sample size was 156 samples. ${ }^{a p}$-value for multivariate logistic regressions; constant $=-0.375$.

Abbreviation: Ref, reference group.

a dental appointment in the previous year. This observation was inconsistent with the existing evidence. Hence, these 33 participants may possibly face some inexplicit difficulties to access UC dental care services of Thailand and that was reasonable for further investigation on their perspectives and experiences. Consequently, participants in the 3 focus groups (each comprising 11 participants) were wheelchair users with education $>$ primary education, who did not go to see a dentist in the previous 12 months. Table 4 presents the general characteristics of participants included in the qualitative phase. They were mostly women (57.6\%), living independently with a median Barthel ADL score of 17, aged 22-57 years (median: 49 years), with an income $<15,000$ THB ( 475 USD) per month $(81.8 \%)$, and giving negative responses for questions regarding dimensions of access.

The main results of the 3 focus groups were reported as follows:

\section{Accessibility}

The majority of participants (26/33) did not attend a dental service due to inconvenience, distance, and their particular support needs.

It is difficult to go a long distance by myself. I didn't want to ask for a favor from my family or friends if it was not necessary. I never had a dental problem. [participant 8, focus group 2]
Table 4 Demographic characteristics of participants included in qualitative phase

\begin{tabular}{ll}
\hline Variables & $\begin{array}{l}\text { Number (\%) or } \\
\text { median (range) }\end{array}$ \\
\hline Total & $33(100)$ \\
Barthel ADL scores & $17(14-19)$ \\
Age (years) & $49(22-57)$ \\
Gender & \\
Female & $19(57.6)$ \\
Male & $14(42.4)$ \\
Income per month & \\
$\geq 15,000$ THB & $6(18.2)$ \\
$<15,000$ THB & $27(81.8)$ \\
Education & \\
$>$ Primary & $33(100)$ \\
SPrimary & 0 \\
Dimensions of access & \\
Accessibility & \\
Yes & \\
No & $7(21.2)$ \\
Availability & $26(78.8)$ \\
Yes & \\
No & $8(24.2)$ \\
Acceptability & $25(75.8)$ \\
Yes & \\
No & \\
Affordability & $9(27.3)$ \\
Yes & $24(72.7)$ \\
No & \\
Accommodation & $6(18.2)$ \\
Yes & $27(81.8)$ \\
No & \\
Awareness & $25(75.8)$ \\
Yes & \\
No & \\
\hline A & \\
\hline
\end{tabular}

Abbreviation: ADL, activity of daily living.

I went to the Health Promoting Hospital located in my community for a diabetes check-up appointment, but there is no dentist at this community hospital. If I wanted to see a dentist, I had to go to the province hospital that is quite far from my home. I never had a toothache, so I didn't want to go. [participant 5, focus group 1]

I used to go to the province hospital, where there were many patients. I went there for a tooth extraction waiting from 5 am, but I didn't get the treatment because they were limited to only ten outpatients per day. It took approximately an hour driving from my home to the hospital. [participant 12, focus group 3]

\section{Availability}

Most participants (25/33) had experienced a dental staff refusal for providing dental services because there was no 
dentist available for the special needs of individuals with disabilities and inappropriate dental equipment.

I used to go to a dental clinic in my community but there was no specialist for individuals with disabilities. After that, I took medicine whenever I had pain. [participant 8, focus group 3]

A dental nurse told me that her community hospital did not have specific equipment for the care of disabled patients. [participant 9, focus group 2]

Two or three years ago, even the province hospital did not have a specialist for disabled individuals. Then a dental nurse suggested that I go to a university hospital in Bangkok. [participant 13, focus group 1]

\section{Acceptability}

Most participants (24/33) reported feelings of discrimination and insecurity (when in a dental chair).

I didn't understand why they (dentists, dental nurses) always told me that they did not have appropriate equipment and they were not specialists for individuals with disabilities. We also have teeth. [participant 1 , focus group 1]

I didn't want to see dentists; I felt like I was bothering them. Some dental staff preferred patients without disabilities. [participant 5, focus group 2]

I felt very unstable and insecure on a dental chair (out of my wheelchair). I was like a doll; both of my hands were weak from grabbing and my legs became paralyzed. What would could I do if I fell off the dental chair? I didn't want to have more complex disabilities. Dental treatments were terrible. [participant 13, focus group 3]

\section{Affordability}

Approximately $82 \%$ of participants (27/33) reported insufficient dental benefits and private traveling expenses, as well as the need for extra transfer payments.

It (dental treatment) was very expensive. The government UC scheme supported only primary dental treatments, but did not offer full coverage. Furthermore, I had to pay for a taxi. [participant 2, focus group 2]

I had to pay for private transportation, such as a taxi or a van, because public transport is not convenient for wheelchair users. [participant 7, focus group 3]

I had to pay someone to move me out of my wheelchair and transfer me to a dental chair. I would not have needed to pay hospital staff, but I felt guilty because my weight was more than a hundred kilograms. [participant 3, focus group 1]

\section{Accommodation}

Nearly $76 \%$ of participants $(25 / 33)$ reported difficulties with obtaining a dental appointment, inappropriate referral systems, and barriers of access to buildings.

I tried to call a district hospital to make a dental appointment, but I could not. They suggested I go to the hospital in the early morning as an outpatient the first time, then I could make an appointment for my next dental visit. However, the quota of outpatients per day was limited and many patients without disabilities also needed dental treatments. They didn't have a track of dental service appointment for disabled patients. [participant 4 , focus group 1]

Dental staff tended to refer me again and again. From the first hospital I was referred to a second hospital, and the second hospital then referred me to a third hospital. they were not ready for my disability or something. [participant 10, focus group 3]

My wheelchair could not get into the dental clinic. It had many steps and a narrow door. [participant 3, focus group 2]

\section{Awareness}

Most participants (25/33) had limited oral health literacy and lacked knowledge of their dental benefits and entitlements.

I brush my teeth once a day, only in the morning. [participant 13, focus group 2]

I couldn't see the "root of my tooth." Where is the root of a tooth in my mouth? [participant 9, focus group 1]

I didn't know about my dental benefits and entitlements. [participant 2, focus group 3]

\section{Discussion}

This study presents the first evidence of the perspectives and experiences of Thai adults using wheelchairs regarding barriers of access to dental services. Prior studies ${ }^{22,23}$ mention that individuals with disabilities living in care institutions were more likely to meet dentists as routine dental care than those living independently in community households, who were less likely to have a dental appointment, ${ }^{23}$ and may possibly be at a higher risk for oral diseases. ${ }^{22,23}$ Our participants of community dwelling wheelchair users, therefore, may have encompassed the Thai individual with physical disabilities most at risk for unmet dental care needs. Although all participants in this study relied on the government's UC scheme, the majority had irregular dental service attendance. Moreover, the results from 3 focus groups suggest generally negative views about Thai dental services for all dimensions of access. 
In the quantitative phase, simple bivariate and multivariate analyses presented the significant associations between dental service attendance and education level (Table 3). The multivariate analysis indicated that participants who had education level $\leq$ primary education were more likely to had not attended at least 1 dental appointment in the previous year. This finding was consistent with previous studies ${ }^{19-21}$ have reported that individuals with higher education are more likely to have regular dental service attendance. Regarding the dimensions of access, ${ }^{14,15}$ there was no significant association in the binary logistic regression analyses; the bivariate analyses showed relations between dental service attendance and the 3 dimensions of access (accessibility, acceptability, and accommodation) with $P$-value $<0.23$.

In the qualitative phase, the findings of the 3 focus group discussions provided further details in barriers of access to dental services for Thai individuals with physical disabilities. With regard to "accessibility" (location, distance, and time), participants in this study were wheelchair users and required support from their family and friends for transportation. Therefore, participants preferred to use health care services, including dental services, in their community. However, most community hospitals in Thailand (health promoting hospitals) provide primary health care and are likely not equipped for special care dentistry: Thai individuals with disabilities have to travel more longer distance for their special needs dental care at secondary or tertiary care hospitals. ${ }^{3}$ Our findings are similar to those reported in earlier studies, ${ }^{2,4,23}$ which suggest that wheelchair users tend to have difficulties with traveling and transportation for dental health care.

The "availability" dimension relates to the adequacy of dental staff and the presence of appropriate resources for wheelchair users. Most participants reported negative experiences in this dimension. These perspectives are consistent with observations reported in previous studies ${ }^{7,8,24}$ indicating a lack of specialty skills and the limited workplace facilities of dental service for people with disabilities in Thailand. Moreover, an earlier study ${ }^{23}$ also mentions a lack of trained special care dentists as a notable barrier of access to dental services among disabled individuals. Therefore, existing studies ${ }^{25-27}$ have suggested that it is important for dental staffs to develop the essential skills and sufficient experience treating individuals with special needs to ensure access for all to oral health care.

"Acceptability" refers to the participants' attitudes toward dental staff. Feelings of discrimination and insecurity emerged from all focus group discussions. Such experiences of discrimination were also reported in a recent study from
Canada. ${ }^{4}$ In the Thai context, a prior study ${ }^{24}$ reports that Thai dental staff are worried about difficulties in communication and behavioral management for disabled patients. Moreover, a well-organized consultation system for special care dentistry has not been established in Thailand. 3,7,8,24,27 Such reports suggest that dental staff do not mean to discriminate, but lack communication and special care dentistry skills..$^{24,28}$ However, the use of warm and friendly communication should be considered. ${ }^{9}$ Many participants also reported feeling insecure in a dental chair (when out of their own wheelchairs). Participants with physical disabilities in previous studies have also reported discomfort in the dental chair ${ }^{4}$ and dental fear. ${ }^{2}$ However, due to variations in disability conditions, dental staff should ask their patients how much or little support they require. ${ }^{9}$

We also investigated "affordability" among our focus group participants. It should be noted that Thai citizens with disabilities rely on the government UC scheme. Therefore, they are entitled to receive primary dental care services, such as tooth extraction, tooth filling, preventive dentistry, dental prophylaxis, and acrylic dentures. ${ }^{3}$ The Thai government also provides support for individuals with disabilities in terms of public transportation. Nevertheless, most participants reported insufficient dental benefits and travel expenses, and the need to pay extra for someone to transfer an individual with physical disabilities from a wheelchair to a dental chair. Some observations were consistent with previous studies, such as reports of insufficient dental insurance, ${ }^{4,29}$ expensive dental procedures, ${ }^{4,29}$ and high private transportation fees. ${ }^{23}$ To our knowledge, the need for extra payment for transfer to a dental chair has only been observed in the Thai context.

"Accommodation" represents whether dental services are well organized for the use of wheelchair users, and most of our participants expressed negative experiences in this dimension. This is consistent with several previous studies ${ }^{2,4,23,28,29}$ which have reported several difficulties of access to dental services among wheelchair users, including inappropriate appointment systems, limited numbers of dental cases per day, poor referral systems, and architectural barriers. In Thailand, these reflections can be explained by a lack of specific policy on dental services for individuals with disabilities as suggested in previous evidence. . $7,8,24,27^{2}$

"Awareness" refers to the provision of information and oral health literacy. Some studies ${ }^{19,20}$ have reported that more highly educated individuals more likely regularly attend dental services. Moreover, a few studies ${ }^{30,31}$ have reported an association between limited oral health literacy and a greater risk of missed dental appointments. However, all participants 
in our 3 focus groups had an education level >primary education, but still had not attended dental appointments within the previous 12 months. Furthermore, they tended to have limited knowledge regarding oral health and dental entitlements, which can lead to improper oral health behaviors and irregular dental attendance.

This study is subject to limitations. Although the study reflects the unheard voices of wheelchair users in Thailand, it is important to note that they may not be representative of all Thai people using wheelchairs. We focused on the barriers of access to dental services, thus the positive views were limited. Consequently, a qualitative study on perspectives of wheelchair users who went to see a dentist in the previous 12 months regarding challenges of dental service attendance and a large-scale survey of this topic are recommended.

\section{Conclusion}

This study has uncovered the perspectives and experiences of Thai adults using wheelchairs regarding barriers of access to dental services. Although some of these difficulties have been reported in previous scientific evidence, the challenges of access to dental care among individuals with disabilities still remain in Thailand ${ }^{3,7,8}$ such the same as in many other countries. ${ }^{2,4,23,28,29}$ Based on the findings in this study, Thai individuals with physical disabilities using wheelchairs are in need of oral health knowledge. Therefore, oral health education programs by oral health professionals regarding proper oral health behaviors, such as regular dental service attendance, appropriate oral hygiene practices, and dental care benefits, should be implemented for disabled individuals, including their care givers. Moreover, for breaking down the barriers to UC, ${ }^{32}$ policy makers in Thailand oral health system should be alerted to the explicit barriers reported such that equitable and equal dental services for disabled individuals can be developed.

\section{Acknowledgment}

This study was supported by the 90th Anniversary of Chulalongkorn University Fund (Ratchadaphiseksomphot Endowment Fund) GCUGR1125612051D, Chulalongkorn University, Bangkok, Thailand.

\section{Disclosure}

The authors report no conflicts of interest in this work.

\section{References}

1. World Health Organization. Global disability action plan 2014-2021. Better health for all people with disability; 2015. Available from: http:// apps.who.int/iris/bitstream/10665/199544/1/9789241509619_eng.pdf. Accessed August 7, 2018.
2. Yuen HK, Wolf BJ, Bandyopadhyay D, Magruder KM, Selassie AW, Salinas CF. Factors that limit access to dental care for adults with spinal cord injury. Spec Care Dentist. 2010;30(4):151-156.

3. Chimruang J, Sermsuti-Anuwat N. Scoping Review and Research Synthesis on the Financial Management of Oral Health Promotion System for the Disabled in Thailand. J Health Syst Res. 2012;6(2):278-289.

4. Rashid-Kandvani F, Nicolau B, Bedos C. Access to Dental Services for People Using a Wheelchair. Am J Public Health. 2015;105(11): 2312-2317.

5. Kothari M, Pillai RS, Kothari SF, Spin-Neto R, Kumar A, Nielsen JF. Oral health status in patients with acquired brain injury: a systematic review. Oral Surg Oral Med Oral Pathol Oral Radiol. 2017;123(2):205.e7-219.e7.

6. Pan MY, Hsieh TC, Tai HC, Lin MS, Lin YC, Chen MY. Prevalence of and factors associated with fewer than 20 remaining teeth in Taiwanese adults with disabilities: a community-based cross-sectional study. $B M J$ Open. 2017;7(10):e016270.

7. The Institute of Health Promotion for People with Disability. The 2016 Evaluation Report of Oral Health for Individuals with Disabilities in Thailand. Thailand: 2016.

8. This project was supported by Thai Health Promotion Foundation. The 2017 Report of the Development of An Innovative Delivery Process of Oral Health care for Thai Disabled People Project. Thailand: 2017.

9. Dougall A, Fiske J. Access to special care dentistry, part 1. Access. $\mathrm{Br}$ Dent J. 2008;204(11):605-616.

10. National Statistical Office, Ministry of Information and Communication Technology. The 2012 Disability Thailand National Survey. Thailand; 2012. Available from: http://service.nso.go.th/nso/nsopublish/service/ survey/disabilityRep_55.pdf. Accessed August 7, 2018.

11. Khongboon P, Pongpanich S, Chapman RS. Risk Factors for Six Types of Disability among the Older People in Thailand in 2002, 2007, and 2011. J Aging Res. 2016;2016:6475029.

12. Singh AS, Masuku MB. Sampling Techniques \& Determination of Sample Size In Applied Statistics Research: An Overview. Int J Econ Commerce Manag. 2014;2(11):1-22.

13. Medicine IOG. Guidelines for the elderly clinic. Institute Of Geriatric Medicine, Department of Medical Services, Ministry of Public Health. Thailand; 2013:12-13. Available from: http://www.msd.bangkok.go.th/ manual\%20clinic\%20older\%20people.pdf. Accessed August 7, 2018.

14. Penchansky R, Thomas JW. The concept of access: definition and relationship to consumer satisfaction. Med Care. 1981;19(2):127-140.

15. Saurman E. Improving access: modifying Penchansky and Thomas's Theory of Access. J Health Serv Res Policy. 2016;21(1):36-39.

16. Tong A, Sainsbury P, Craig J. Consolidated criteria for reporting qualitative research (COREQ): a 32-item checklist for interviews and focus groups. Int J Qual Health Care. 2007;19(6):349-357.

17. Braun V, Clarke V. Using thematic analysis in psychology. Qual Res Psychol. 2006;3(2):77-101.

18. Braun V, Clarke V. What can "thematic analysis" offer health and wellbeing researchers? Int J Qual Stud Health Well-Being. 2014;9:26152.

19. Guiney H, Woods N, Whelton H, Morgan K. Predictors of utilisation of dental care services in a nationally representative sample of adults. Community Dent Health. 2011;28(4):269-273.

20. van der Heyden JH, Demarest S, Tafforeau J, van Oyen H. Socioeconomic differences in the utilisation of health services in Belgium. Health Policy. 2003;65(2):153-165.

21. El Osta N, El Osta L, Khabbaz LR, et al. Social inequalities in oral health in a group of older people in a Middle Eastern country: a crosssectional survey. Aging Clin Exp Res. 2018.

22. Horner-Johnson W, Dobbertin K, Beilstein-Wedel E. Disparities in dental care associated with disability and race and ethnicity. $J$ Am Dent Assoc. 2015;146(6):366-374.

23. Pradhan A, Slade GD, Spencer AJ. Access to dental care among adults with physical and intellectual disabilities: residence factors. Aust Dent $J$. 2009;54(3):204-211. 
24. Burapholkul P. Limitations and barriers of dentists to dental care for people with intellectual disability in Thailand. Thailand J Dent Public Health. 2008;13(5):7-16.

25. Faulks D, Freedman L, Thompson S, Sagheri D, Dougall A. The value of education in special care dentistry as a means of reducing inequalities in oral health. Eur J Dent Educ. 2012;16(4):195-201.

26. Dao LP, Zwetchkenbaum S, Inglehart MR. General dentists and special needs patients: does dental education matter? J Dent Educ. 2005; 69(10):1107-1115.

27. Saengtipbovorn S, Taneepanichskul S, Pongpanich S, Boonyamanond L. Factors associated with the utilization of dental health services by the elderly patients in health center no.54, Bangkok, Thailand. J Health Res. 2012;26(4):199-204.

28. Leal Rocha L. Vieira de Lima Saintrain M, Pimentel Gomes Fernandes Vieira-Meyer A. Access to dental public services by disabled persons. BMC Oral Health. 2015;15:35.
29. Rouleau T, Harrington A, Brennan M, et al. Receipt of dental care and barriers encountered by persons with disabilities. Spec Care Dentist. 2011; 31(2):63-67.

30. Holtzman JS, Atchison KA, Gironda MW, Radbod R, Gornbein J. The association between oral health literacy and failed appointments in adults attending a university-based general dental clinic. Community Dent Oral Epidemiol. 2014;42(3):263-270.

31. Mcquistan MR. Poor Oral Health Literacy May Lead to Missed Dental Appointments. J Evid Based Dent Pract. 2017;17(4):422-424.

32. Sakolsatayadorn P, Chan M. Breaking down the barriers to universal health coverage. Bull World Health Organ. 2017;95(2):86.

\section{Publish your work in this journal}

Patient Preference and Adherence is an international, peer-reviewed, open access journal that focuses on the growing importance of patient preference and adherence throughout the therapeutic continuum. Patient satisfaction, acceptability, quality of life, compliance, persistence and their role in developing new therapeutic modalities and compounds to optimize clinical outcomes for existing disease states are major areas of interest for the journal. This journal has been accepted for indexing on PubMed Central. The manuscript management system is completely online and includes a very quick and fair peer-review system, which is all easy to use. Visit http://www. dovepress.com/testimonials.php to read real quotes from published authors.

\footnotetext{
Submit your manuscript here: http://www.dovepress.com/patient-preference-and-adherence-journal
} 